\title{
Toward Improving the Representation of Anvil Cirrus Effects in GCMs
}

\author{
Hung-Neng S. Chin and Michael M. Bradley \\ Regional Atmospheric Sciences Division \\ Lawrence Livermore National Laboratory \\ P.O. Box 808, L-262 \\ Livermore, California 94551 USA
}

This paper was prepared for submittal to the Atmospheric Radiation Measurement

Science Team Annual Meeting

San Diego, CA

March 20-23, 1995

April 30, 1995

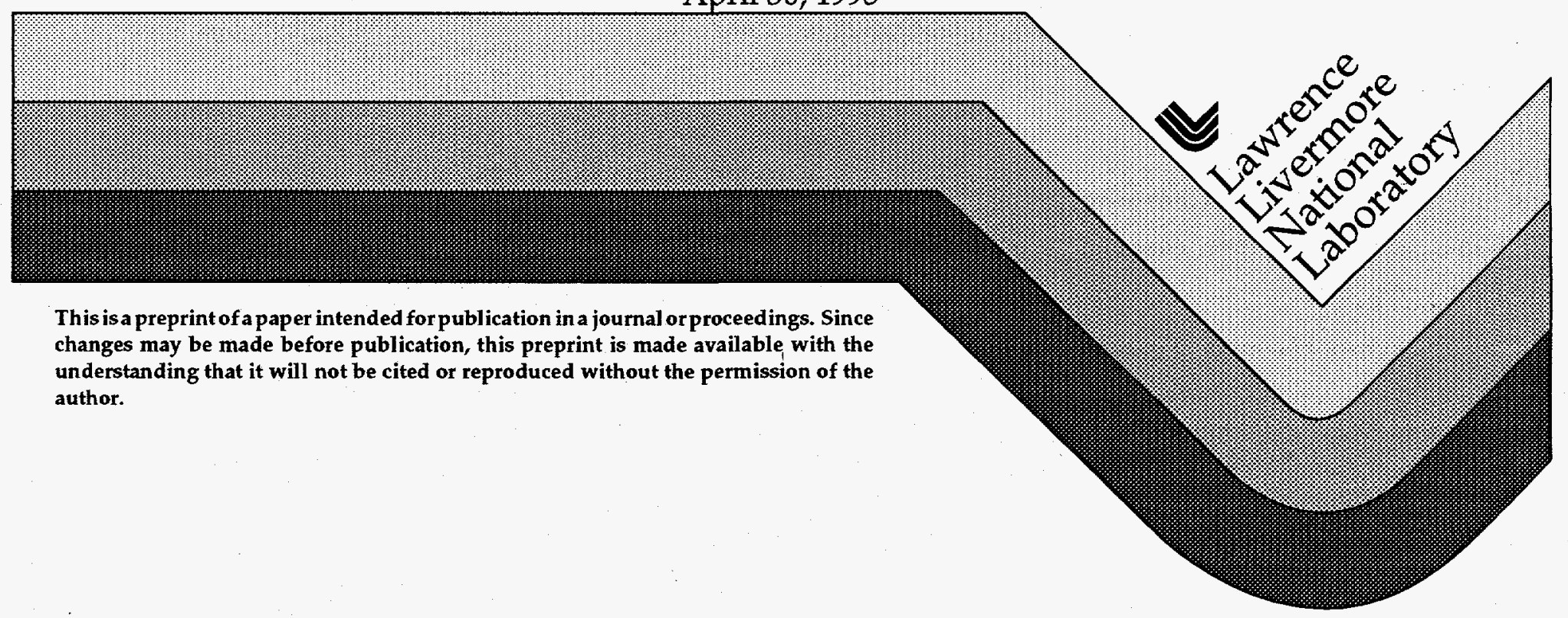




\section{DISCLAIMER}

This document was prepared as an account of work sponsored by an agency of the United States Government. Neither the United States Government nor the University of California nor any of their employees, makes any warranty, express or implied, or assumes any legal liability or responsibility for the accuracy, completeness, or usefulness of any information, apparatus, product, or process disclosed, or represents that its use would not infringe privately owned rights. Reference herein to any specific commercial product, process, or service by trade name, trademark, manufacturer, or otherwise, does not necessarily constitute or imply its endorsement, recommendation, or favoring by the United States Government or the University of California. The views and opinions of authors expressed herein do not necessarily state or reflect those of the United States Government or the University of California, and shall not be used for advertising or product endorsement purposes. 


\section{DISCLAIMER}

Portions of this document may be illegible in electronic image products. Images are produced from the best available original document. 


\title{
Toward Improving the Representation of Anvil Cirrus Effects in GCMs
}

\author{
Hung-Neng S. Chin and Michael M. Bradley \\ Regional Atmospheric Sciences Division \\ Lawrence Livermore National Laboratory
}

\section{INTRODUCTION}

Cloud-radiation feedback has been identified as the most important factor limiting general circulation models (GCMs) to further progress in climate change research (Cess et al., 1989). It is also regarded as a major uncertainty in estimating the impact of greenhouse gases on climate simulations (Schlesinger and Mitchell, 1987). Many GCMs show high sensitivity to the treatment of clouds and cloud radiative properties (e.g., Randall et al., 1989; Mitchell et al., 1989). Therefore, a better understanding of cloud-radiation feedback on the large-scale environment is absolutely essential to improve the representation of cloud processes in GCMs.

To this end, a cloud model with enhanced model physics is used to study the impact of cloud-radiation interactions on mesoscale convective systems (MCSs). Case studies representing a variety of convective systems are important to generalize the overall effects of anvil clouds on the large-scale environment. Our primary interest is limited to MCSs in an environment with substantial wind shear, such as squall-line systems, because they have longer lifetimes and wider coverage to impact the earth radiation budget and climate.

Recent studies (Chin, 1994; Chin et al., 1995 and many others) indicated that the vertical shear of the environmental wind plays an important role in the formation of the anvil cloud through the tilting of MCSs. However, this process has not been represented in GCMs. A detailed investigation on the formation of anvil clouds and their relationship to cumulus portions of MCSs would help develop a better cloud parameterization for use in GCMs.

Comparisons between simulated midlatitude (Oklahoma) and tropical (GATE) squall-line systems are presented in this study. Two important issues are addressed through these comparisons. First, what factors cause the differences between midlatitude and tropical anvil clouds? Second, do these differences have climatic implications to improve our climate forecasting ability?

\section{MODEL AND INITIALIZATION}

The model used is an extension of Chin and Ogura's (1989) two-dimensional cloud model, which is nonhydrostatic and fully compressible. The major improvements include ice microphysics and radiation transfer schemes for long- (LW) and shortwave (SW). The modified parameterizations of ice microphysics

Corresponding author address: Dr. H.-N. S. Chin, P. O. Box 808 (L-262), Livermore, CA 94551. and radiation can simulate midlatitude and tropical squall-line systems with prominent anvils and realistic mesoscale structures. The radiation schemes can distinguish the impacts of hydrometeor phase, size, and shape on cloud optical properties.

Refer to Chin (1994) and Chin et al. (1995) for the details of model physics, grid structures and initial conditions of both midlatitude and tropical cases. Based on Weisman and Klemp (1984), the bulk Richardson numbers of midlatitude and tropical soundings (74 and 52 , respectively) favor the development of multicellular storms.

The model is initialized by a warm, moist bubble and a horizontally homogeneous sounding. However, the tropical case also includes the large-scale ascent. Our sensitivity tests indicate that an organized tropical oceanic squall-line system cannot develop without the imposed large-scale ascent.

\section{RESULTS}

To estimate the degradation in GCM accuracy caused by omitting individual processes, we conducted a series of simulations for midlatitude broken-line and tropical oceanic squall-line systems. These simulations use different combinations of radiation and microphysics complexity, ranging from no radiation and only liquid microphysics to both $\mathrm{LW}$ and $\mathrm{SW}$ radiation with full liquid and ice microphysics. To validate our results, we compared the simulations with observations (Smull and Houze, 1987; Houze, 1977).

\section{a. Impact on Dynamic and Microphysical Structures}

The general patterns of the dynamic and microphysical structures of the simulated midlatitude and tropical squall-line systems (Figs. 1 and 2) were very similar to the observed features, that include the upshear tilting of convective cores, the broad stratiform precipitation region, the strong slant rear-to-front inflow with the outflow above and below, a bright melting band and a well-defined transition zone in the radar reflectivity.

Our results show that both ice-phase microphysics and radiation have little influence on the multicellular character of the modeled midlatitude and tropical squall-line systems. Although both simulated systems exhibit strong similarities in the dynamic and microphysical structures, different environmental conditions, such as the presence or absence of the jet wind profile and thermodynamical stability, still cause substantial differences. These differences include a weaker upper-level leading and stronger upper-level 
trailing outflow, and a stronger and broader trailing anvil cloud in the tropical squall-line system.

System-relative Horizontal Velocity $\left(\mathrm{m} \mathrm{s}^{-1}\right)$
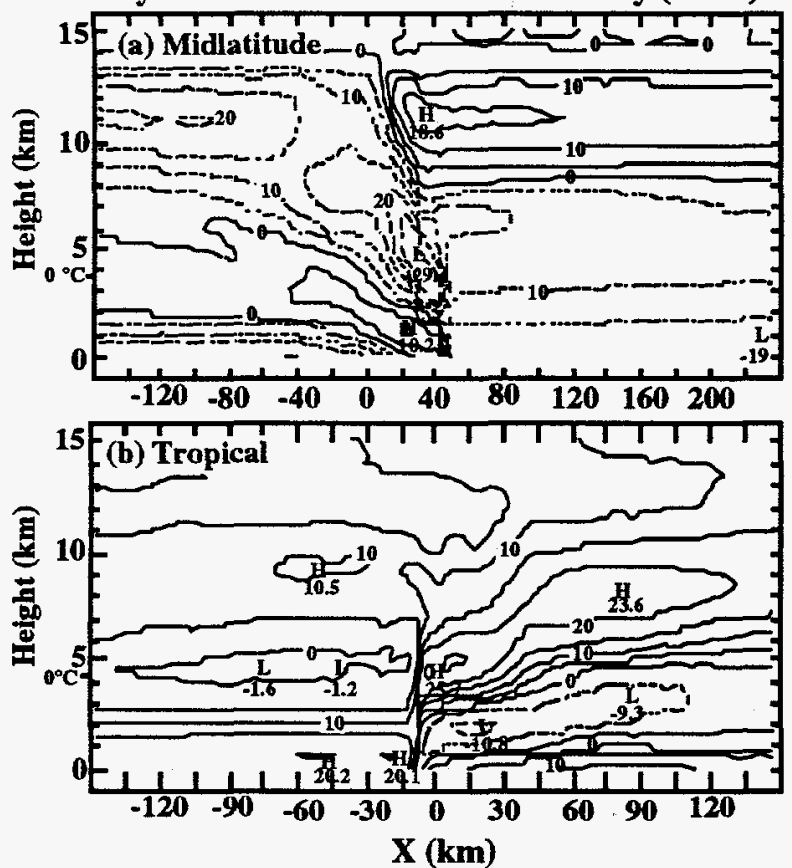

Fig. 1. Temporally averaged cross-sections of systemrelative horizontal velocities at the mature stage of the simulated squall-line systems. midlatitude case. (b) tropical case.

(a)

Model-derived Radar Reflectivity (dBZ)
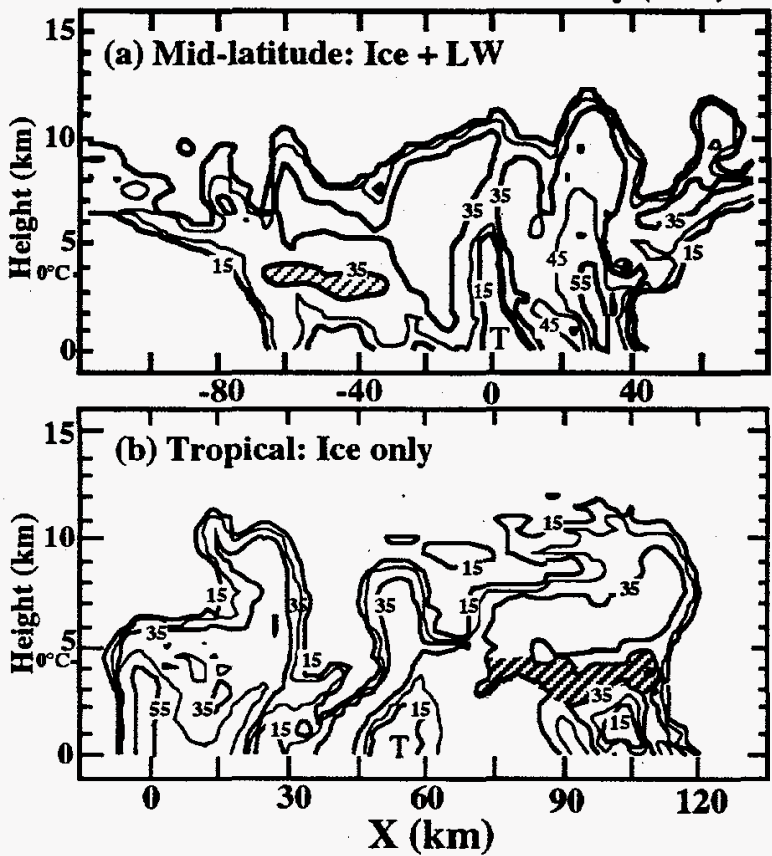

Fig. 2. Instantaneous model-derived radar reflectivities near the late mature stage of simulated squallline systems. Shaded area represents the bright melting band and $T$ marks the location of the transition zone. (a) mid-latitude case. (b) tropical case.

\section{b. Impact on moisture and water Budget}

To assess the contribution of moisture (i.e., water vapor) transport by deep convection to the formation of simulated anvil clouds, the moisture budget is calculated for both simulated tropical and midlatitude squall-line systems (Fig. 3). For the direct comparison, the values shown in the tropical and midlatitude moisture budgets are normalized by total surface precipitation $\left(\mathrm{P}_{0}\right)$ of the tropical case.

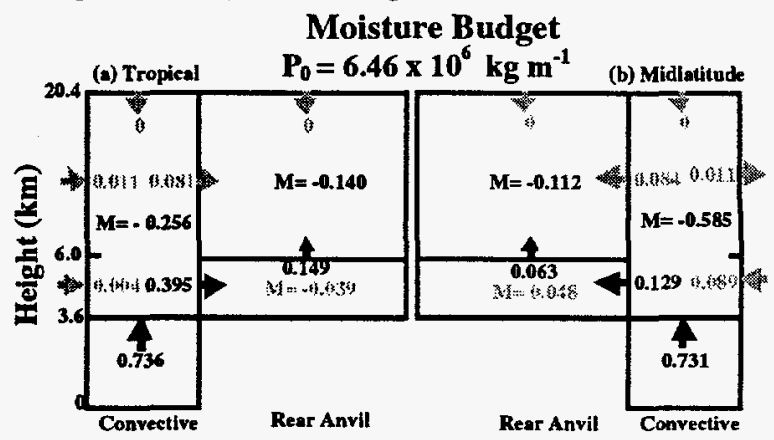

Fig. 3. The moisture budgets at the mature stage of the simulated squall-line systems. (a) tropical case. (b) midlatitude case. All quantities are normalized by total surface precipitation of the tropical control run $\left(\mathrm{P}_{0}\right)$. M represents the net depletion by microphysical processes; small arrows, horizontal and vertical moisture transport.

Interestingly, moisture transport from the lower tropical and midlatitude convective regions (below 3.6 $\mathrm{km}$ ) are about the same; this is because the very moist low-level tropical atmosphere compensates for the weaker convective instability in the tropics. In addition, the weaker and lower deep convection in the tropical case depletes much less moisture through net condensation/deposition at the upper levels of the convective region (above $3.6 \mathrm{~km}$ ). As a result, more moisture at the upper levels is transported rearward to form the anvil cloud in the tropical case. In addition, the larger upper-level moisture depletion by condensation/deposition and stronger vertical moisture transport by mesoscale lifting at $6 \mathrm{~km}$ in the tropical anvil region is an indication of stronger mesoscale ascent associated with the tilting structure of the simulated squall-line system. Similar features are also found in moisture transport at the lower level for the mesoscale descent. As a whole, these moisture budgets indicate that tropical deep convection serves as a more efficient engine pumping low-level moisture into the upper-level anvil cloud than its midlatitude counterpart.

The water (i.e., condensate) budget for the midlatitude case indicates that hydrometeor transport by deep convection is the primary contributor to the water source of the anvil cloud at the mature stage (66\%; defined as the ratio of horizontal transport to the sum of horizontal transport and microphysical production). The rest of the water budget in the midlatitude anvil (34\%) is contributed by the mesoscale lifting associated with the tilting convective system in the sheared environment (Fig. 4a). In contrast, deep 
convection contributes only $40 \%$ to the water budget of the tropical anvil and becomes a secondary source (Fig. 4b). The dominant contribution of the water budget in the tropical anvil (60\%) comes from microphysical production $(\mathrm{M})$ in response to the midlevel easterly jet, that enhances the mesoscale circulation and the resulting lifting.

Without the ice phase, the contribution of hydrometeor transport by deep convection to the water budget of anvil clouds is substantially reduced (not shown). In addition, the contribution of microphysical production in the tropical case without the large-scale ascent (not shown) indicates that large-scale ascent only makes a trivial contribution to the convective region and anvil cloud. However, it does play a significant role in maintaining the marine stratus.
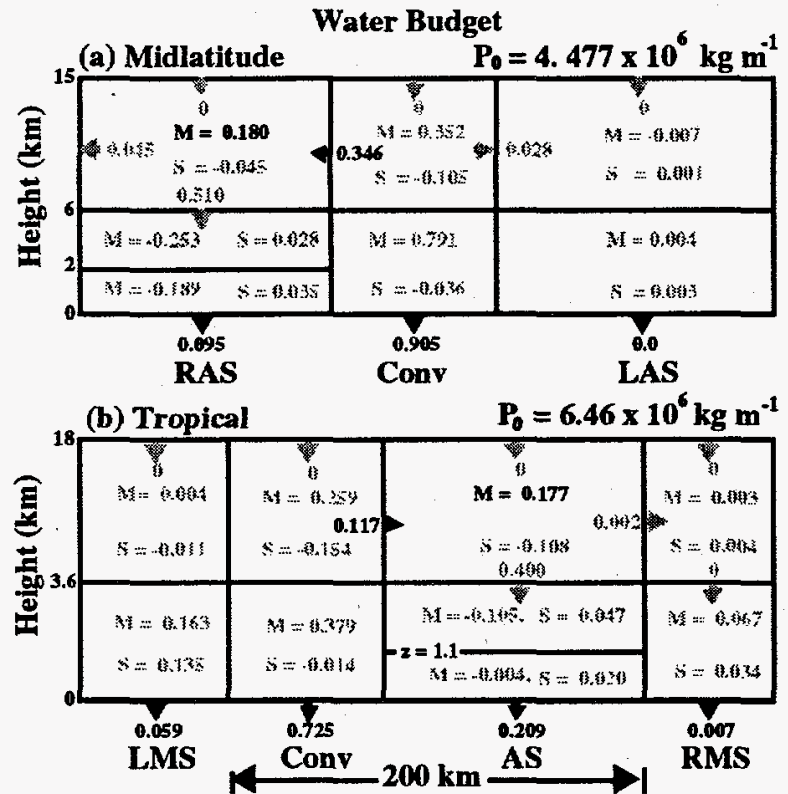

Fig. 4. The water budget for the mature stage of the simulations with ice microphysics and without radiation. (a) midlatitude squall-line system over the central subdomain $(200 \mathrm{~km})$. (b) tropical squall-line system over the whole domain (3560 $\mathrm{km}$ ). All quantities are normalized by the total surface precipitation $\left(\mathrm{P}_{0}\right)$. M represents the net microphysical production; $S$, the storage term; arrows, horizontal and vertical transports; LAS and RAS, leading and rear anvil stratus; Conv, the convective region; LMS and RMS, leading and rear marine stratus; AS, the anvil stratus.

\section{c. Impact on Cloud Optical Properties}

The cloud LW and SW radiative forcings, averaged over the areas of different stratiform cloud regions, are used to assess the impact of stratiform clouds on the radiation budget of the local earth-atmosphere system. The cloud radiative forcing is defined as $\mathrm{F}_{\text {clear }}^{\uparrow}-\mathrm{F}_{\text {cloudy }}^{\uparrow}$, where $\mathrm{F}^{\uparrow}$ is the upward flux at the top of the model atmosphere. As shown in Fig. 5, the cloud SW radiative forcings for all types of stratiform clouds decrease with increasing solar zenith angle, and the tropical anvil cools the local earth-atmosphere system more effectively than the marine stratus and the midlatitude anvil.

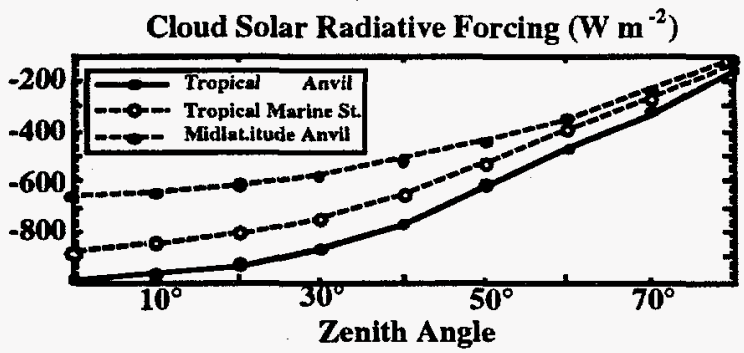

Fig. 5. SW cloud forcing averaged over the area of different stratiform clouds at varied zenith angle.

Based on Manabe and Möller (1961), the daily mean of the cloud SW radiative forcings for different simulated stratiform clouds (the marine stratus and the anvil cloud) during the summer is calculated to compare with its LW counterpart (Table 1). These SW calculations account for the latitudinal variations of daytime fractional length (f) and daily mean of solar zenith angle $(\bar{\zeta})$; $\mathrm{f}$ and $\bar{\zeta}$ are 0.517 and $54.1^{\circ}$ for the tropical case, and 0.637 and $58.6^{\circ}$ for the midlatitude case, respectively.

Table 1. Cloud radiative forcing ( $W \mathrm{~m}^{-2}$ ) for different stratiform clouds.

\begin{tabular}{|c|c|c|c|}
\hline Radiation & LW & $\overline{\text { SW }}^{1}$ & Total \\
\hline Tropical Anvil $^{2}$ & +200 & -290 & -90 \\
\hline Tropical Marine St. $^{2}$ & +20 & -248 & -228 \\
\hline Midlatitude Anvil & +190 & $-2366^{4}$ & -46 \\
\hline
\end{tabular}

1 overbar represents the summer-time daily mean, based on Manabe and Möller (1961).

2 surface albedo $=0.05$ and effective size of ice crystals $=30 \mathrm{~mm}$.

3 surface albedo $=0.2$ and effective size of ice crystals $=75 \mathrm{~mm}$.

4 without considering the latitudinal variations of day-time length and solar zenith angle.

Radiation calculations show that the simulated tropical anvil cloud has larger cloud LW (200 vs. 20 $\mathrm{W} \mathrm{m}^{-2}$ ) and SW radiative forcings (-290 vs. $-248 \mathrm{~W}$ $\mathrm{m}^{-2}$ ) than the tropical marine stratus. This result contradicts a general belief that low/high-level cloud acts to cool/warm the earth-atmosphere system. Nevertheless, the optically thick anvil cloud was proposed to act as a thermodynamical regulator to limit sea surface temperature (Ramanathan and Collins 1991) using Earth Radiation Budget Experiment data. Although the anvil cloud has a smaller total (LW + SW) cloud radiative forcing than the marine stratus, the cloud LW and SW radiative forcings of the anvil cloud 
are much larger than their marine stratiform counterparts. The climatic effects of the anvil cloud are, however, significant because the LW radiative forcing is largely confined to the atmosphere and its SW counterpart is mainly felt at the surface (Ramanathan 1987). Thus, anvil clouds must be appropriately represented in GCMs to improve cloud radiative feedback on large-scale climate.

Further, simulated tropical oceanic and midlatitude continental anvils have comparable cloud $\mathrm{LW}$ radiative forcings ( 200 vs. $190 \mathrm{~W} \mathrm{~m}^{-2}$ ). The comparison of cloud SW radiative forcings between tropical oceanic and midlatitude continental anvils $(-290$ vs. $-236 \mathrm{~W}$ $\mathrm{m}^{-2}$ ) also shows that the tropical oceanic anvil plays a more important role than the midlatitude continental anvil in reducing the effect of $\mathrm{SW}$ insolation on the earth-atmosphere system. Without considering the latitudinal variations of $f$ and $\bar{\zeta}$, this difference is increased from 54 to $78 \mathrm{~W} \mathrm{~m}^{-2}$ by lowering the $S W$ forcing of midlatitude continental anvil to $-212 \mathrm{~W} \mathrm{~m}^{-2}$. Based on these calculations, the larger SW radiative forcing of the tropical oceanic anvil is mainly attributed to a smaller surface albedo and smaller ice crystal size with both factors about equally contributing to the difference, while the variation of $f$ and $\bar{\zeta}$ can cancel out this difference by about one third.

\section{SUMMARY AND DISCUSSION}

Our results show that the tilting structure of MCSs in an environment with substantial wind shear makes an important contribution to the water budget of anvil clouds, particularly the tropical anvil due to the impact of the mid-level easterly jet on enhancing the mesoscale circulation. This implies that a cumulus parameterization would considerably underestimate the cloud beating and drying effects of the tropical squallline system if the mesoscale organization of MCSs was not considered. Comparisons of water budgets between mid-latitude and tropical anvils also have an important implication for climate research due to the strong SW radiative forcing of the tropical anvil. The moisture budgets also indicate that tropical deep convection serves as a more efficient engine pumping low-level moisture into the upper-level anvil cloud than its midlatitude counterpart

The high sensitivity of the dynamical and microphysical structures of the simulated squall-line systems to wind-shear profiles (jet or non-jet) suggests that momentum transport by clouds in different types of sheared environments may provide an important physical basis linking GCM-resolvable variables with the mesoscale lifting associated with the tilting structure of convective systems. Unfortunately, this tilting structure cannot be resolved by GCM grids and no current cumulus parameterization scheme represents these sub-GCM-grid processes and their resulting feedback on the large-scale environment. Therefore, parameterizing the large-scale effects of these subGCM-grid processes associated with the tilting structure of MCSs is a crucial issue that must be addressed to improve the representation of cloudradiation feedback on large-scale climate.

ACKNOWLEDGMENTS. This work was supported by the Department of Energy (DOE) ARM (Atmospheric Radiation Measurement) program and conducted under the auspices of the U. S. DOE by the Lawrence Livermore National Laboratory under contract No. W-7405-ENG-48.

\section{REFERENCES:}

Cess, R. D., G. L. Potter, J. P. Blanchet, G. J. Boer, S. J. Ghan, J. T. Kiehl, H. LeTruet, Z.-X. Li, X.-Z. Liang, J. F. B. Mitchell, J.-J. Morcrette, D. A. Randall, M. E. Riches, E. Roeckner, U. Schlese, A. Slingo, K. E. Taylor, W. M. Washington, R. T Wetherald, and I. Yagai, 1989: Interpretation of cloud-climate feedback as produced in 14 atmospheric general circulation models. Science, 245, 513-516.

Chin, H.-N. S., and Y. Ogura, 1989: Supplementary modeling study of a tropical convective band. $J$. Atmos. Sci., 46, 1440-1447.

Chin, H.-N. S., 1994: The impact of the ice phase and radiation on a mid-latitude squall line. J. Atmos. $S c i ., 51$, in press.

Chin, H.-N. S., Q. Fu, M. M. Bradley, and C. R. Molenkamp, 1995: Modeling of a tropical squall line in two dimensions and its sensitivity to environmental winds and radiation. J. Atmos. Sci., (accepted).

Houze, R. A., Jr., 1977: Structure and dynamics of a tropical squall-line system. Mon. Wea. Rev., 105, 1540-1567.

Manabe, S., and F. Möller, 1961: On the radiative equilibrium and heat balance of the atmosphere. Mon. Wea. Rev., 89, 503-532.

Mitchell, J. F. B., C. A. Senior, and W. J. Ingram, 1989: $\mathrm{CO}_{2}$ and climate: $A$ missing feedback, Nature, 341, 132-134.

Ramanathan, V., 1987: The role of earth radiation budget studies in climate and general circulation research. J. Geophys. Res., 92, 4075-4095.

-.-., and W. Collins, 1991: Thermodynamic regulation of ocean warming by cirrus clouds deduced from the 1987 El-Nino. Nature, 351, 27-32.

Randall, O. A., Harshvardhan, D. A. Dazlich, and T. G. Corsetti, 1989: Interactions among radiation, convection, and large-scale dynamics in a general circulation model. J. Atmos. Sci., 46, 1943-1970.

Schlesinger, M. E., and J. F. B. Mitchell, 1987: Climate model simulations of the equilibrium climatic response to increased carbon dioxide. Rev. Geophys., 25, 760-798.

Smull, B., and R. A. Houze, Jr., 1987: Rear inflow in squall lines with trailing stratiform precipitation. Mon. Wea. Rev., 115, 2869-2889.

Weisman, M. L., and J. B. Klemp, 1984: The dependence of numerically simulated convective storms on vertical wind shear and buoyancy. Mon. Wea. Rev., 110, 504-520. 